\title{
Influences on Urban Competitiveness Development from the Perspectives of Business and Local Authorities
}

\author{
Ruxandra-Irina POPESCU ${ }^{1}$ \\ Răzvan-Andrei CORBOS ${ }^{2}$ \\ Ovidiu-Iulian BUNEA ${ }^{3}$
}

\begin{abstract}
This paper aimed at identifying factors that could support increasing urban competitiveness or on the contrary, which may have negative effects on the level of urban competitiveness. The work highlighted a series of viable actions through which Bucharest could maintain a satisfactory level of urban competitiveness. This was accomplished through an empirical research on the urban competitiveness of Bucharest, which included the analysis of the questionnaire results applied on three large employers in Romania in order to test the hypotheses and to capture the factors that could increase the urban competitiveness of Bucharest. Also, the paper revealed the role of local actors regarding the factors that influence competitiveness and what caused Bucharest's decline in terms of urban competitiveness in 2018 compared to 2017.
\end{abstract}

Keywords: urban competitiveness, urban systems, urban development strategy, local authorities, business

JEL classification: O18; O21; R58.

DOI: $10.24818 /$ RMCI.2018.4.359

\section{Introduction}

European cities are part of the globalized urban system. They have to compete for an advantageous position in the global economy. In addition, they have to attract companies and investors to survive and develop. Urban competitiveness is closely related to the economic and social development of a city, so it is important to maintain or increase the level of competitiveness to ensure the well-being of the inhabitants and to be remarked internationally.

While three-quarters of cities have grown faster than national economies since the early 2000s, there is still room for improvement: many new jobs can be created each year if cities behave like the most competitive metropolis from the

\footnotetext{
${ }^{1}$ Ruxandra-Irina Popescu, The Bucharest University of Economic Studies, Email: ruxandra.irina @ gmail.com, Telephone: 0723569109

2 Răzvan-Andrei Corboș, The Bucharest University of Economic Studies' Email: razvan.corbos @ man.ase.ro' Telephone: 0744486827

3 Ovidiu-Iulian Bunea, The Bucharest University of Economic Studies' Email: ovidiubunea1 @ gmail.com? Telephone: 0724240392
} 
world (Kilroy et al., 2015; Begg, 2002). Increasingly, cities are exposed to greater competition and need to improve their economic performance to keep pace.

Cities are increasingly exposed to global forces as the national state becomes more open to capital and trade flows. This phenomenon is both a threat to market conditions and rapidly changing investments, subjecting urban areas to potential negative economic impacts. At the same time, it is also an opportunity as cities have more opportunities to develop their own competitiveness strategies and can access global markets, foreign labour and capital. However, cities can only control some of the factors that determine their competitiveness (Webster and Muller, 2000).

National political frameworks and socio-economic conditions are also important, for example: national taxes, human resources development, tariffs, incentives, policies, etc. In addition, national political stability has a major influence on the competitiveness of cities.

The purpose of this research is to identify the factors that support the growth of competitiveness or have a negative impact on it and to highlight possible ways for action by which Bucharest can improve its level of urban competitiveness.

\section{Literature Review}

Competitiveness is different from competition. Competition is a zero-toone score, if one city wins, another loses. Instead, all cities can increase their competitiveness at the same time, so that all cities and the national economy grow and benefit simultaneously.

The concept of "urban competitiveness" refers mainly to the ability of a city to create greater and better value with less resources than other cities and to provide welfare to its inhabitants in terms of competition and development (Pengfei \& Qinghu, 2006; Zhang \& Corrie, 2018). According to this definition, long-term economic growth, global market share and general income per capita may indicate the city's competitiveness.

Urban competitiveness targets cities' ability to attract and retain resources in the context of growing competition between regions and states (Turok et al., 2004; Sáez \& Periáñez, 2015). The specificity of urban competitiveness refers to the fact that cities have to compete not only internationally, but also nationally. Competition between cities is focused on investment, human capital, tourism, and cultural and sporting events.

According to Webster et al. (2000), urban competitiveness refers to the capacity of an urban region to produce and market a set of high-quality services and products compared to other cities. An urban economy that produces goods and services for the high-value local population supports the city's export economy, making it more competitive. It also leads to an improvement in the quality of life and standard of living of the city's inhabitants.

360 Review of International Comparative Management Volume 19, Issue 4, October 2018 
The notion of "urban competitiveness" is the competence of a city to attract resources, produce goods and services, market control, effective prosperity creation, and the ability to ensure residents' well-being, in the development process and the conditions of competition, in contrast to other competitors (Pengfei and Qinghu, 2006; Wagner et al., 2017).

Urban competitiveness is the ability of a city to improve its business environment, knowledge base, physical, social, cultural infrastructure and attract and retain profitable, innovative, and creative workforce to enable a rate to be achieved high productivity, employment, high wage levels, gross domestic product per capita, reduced income disparities and diminishing social exclusion (Martin and Simmie, 2008).

Concerning the competition between cities, this occurs because of (Corboş and Popescu, 2013):

- Redirecting economic activities towards more open markets, creating new market conditions where companies can enter other markets;

- With the advent of globalization, cities have focused on fortifying the economic base;

- The contribution to the competitive attitude of cities as a result of decentralization of competences and tasks from the national to the local level.

Urban economies are very specific both in terms of time and space. They have developed their economy over time when certain technologies were also available in the evolution of agriculture, industry, and services. As a consequence, their infrastructure has been realized decades or centuries ago as other city assets the skilled workforce, auxiliary industries, governance structures (Kresl and Ietri, 2015, Buck et al., 2005).

Also, urban economies are linked to natural assets and topographic features. This provides cities with certain advantages and disadvantages in relation to other cities and guides them on the path to development. From the point of view of increasing urban competitiveness, the result is a series of factors that city leaders have to interpret in order to guide the development of their economy.

Urban competitiveness factors (Webster and Muller, 2000):

- More and more, the image is vital in determining the competitiveness of a city. This refers to the profile of a city and is particularly important for smaller towns that are not in the hands of investors or migrants (Webster and Muller, 2000; Jelier, 2017). Currently, urban marketing is an essential component of any urban economic strategy. Examples of this are Hong Kong or Dubai who have aggressively promoted their advantages. The image of a city has a major impact on investors' behaviour, as well as tourists are drawn to a city that projects a strong and positive image.

- Human resources are another important factor that determines urban competitiveness. The capacity of an urban region to enhance its competitiveness is closely linked to human resource capacities. 
- The institutional environment is another aspect, if not the key factor, in building the competitiveness of successful cities, especially in developed economies. Various elements support increased competitiveness.

- Private / public "champions" can enhance competitiveness in several ways (Webster and Muller, 2000). They are people or agents who create energy, enthusiasm and motivation for action and positive change. They are adept at developing interpersonal relationships that facilitate links and open communication that helps build trust. A "champion" can be a charismatic mayor, a development promotion agency or a respected figure (Beal \& Pinson, 2014). They have an essential role in successfully implementing a development strategy and bringing recognition to the city.

According to UN-HABITAT (2010), there are the following factors that influence urban competitiveness:

- Economic factors: production factors, location, infrastructure, economic structure, urban amenities;

- Strategic factors: governmental effectiveness, urban strategy, publicprivate cooperation, institutional flexibility.

External factors, such as national and supranational policies, the structure of the national economy, national fiscal policy, human resources development, accessibility, workforce directly affect the results of a city (Carvalho et al., 2017). Some of the factors are presented in Table 1.

Table 1. Factors that Affect Urban Competitiveness

\begin{tabular}{|cc|}
\hline Category & Elements \\
Human Factors & Work skills \\
& Training and education opportunities \\
Local demographic situation & Local leaders \\
& Innovation / creativity / local talent \\
Local culture / traditions
\end{tabular}

Source: Adapted from Sinkiene, 2009 
Although the factors that affect urban competitiveness are generally similar, the benefits vary from one city to another. Therefore, they have distinct levels of influence, are multidimensional, and have a high degree of complexity $(\mathrm{Ni}$ et al., 2017).

A competitive city is the one that can successfully provide the necessary facilities for its businesses and industries to create jobs, increase productivity, and increase citizens' incomes over time. Improving city competitiveness is a way to eradicate poverty and increase prosperity (Kilroy et al., 2015).

Competitive cities use a set of interventions to increase competitiveness, including institutions and regulations, as well as business support. Each city chooses these interventions according to local circumstances, the political economy, the economic opportunities and the needs of the companies.

There is no unique recipe to become a competitive city, but some patterns can be identified and some techniques can be recommended for cities that develop and implement an economic development strategy. These tools include the strategic analysis of local economy and foreign market trends and opportunities, public private dialogue, techniques to value the political economy during implementation.

Successful cities create a favourable business climate and target economic development initiatives. They use a combination of policies focused on landrelated issues, capital markets, infrastructure, keeping an eye on the needs of different industries and businesses. The most important aspect is consultation, collaboration and partnership with the private sector. Success also involves building coalitions for development with neighbours and other levels of government (Mukim, 2015; Esmaeilpoorarabi et al., 2016).

Cities do not always review their savings to become competitive, but in some cases, they just get better at what they do; manage to make the most of their competitive advantage over competitors.

Competitive cities have paid attention to how to turn strategies into action. They opted for a strategy for economic development, aligned the budget to finance it, solved problems during implementation and mobilized enough staff and interest in the quality of implementation (Kilroy et al., 2015).

The Urban Strategy, in order to facilitate city development so as to lead to the objectives of raising living standards and quality of life, must pursuit (Kornberger, 2012):

- Suitable conditions for maintaining economic prosperity in the medium and long term, enhancing competitiveness;

- Improving living conditions;

- Ability to access high-quality jobs, services and a high standard of living;

- Protecting the environment;

- Improving the quality of governance.

To be able to talk about competitiveness, a city must discover and formulate a unique set of strategies and actions that are appropriate and different 
from those of other cities. The challenge comes from developing a strategy that differentiates the city from the others.

A strategic plan is vital for a city. The strategic planning process consists in identifying the unique, intangible features of a place in reaching a consensus on the vision and direction of action of a city (Zhang, 2014).

\section{Methods}

The research base was made up of three companies operating in Bucharest; the business environment is an important investor whose attraction in Bucharest has a positive influence on the competitiveness of the city.

Three of the companies ranked in Top 100 Most Valuable Companies, 2017 edition, with headquarters in Bucharest, namely: Kaufland, Orange Romania and BRD - GSG, were selected from the number of existing companies in Bucharest. The number of employees of these companies amounts to 18,000 people representing the research population.

A representative sample of 389 respondents to whom questionnaires were applied was obtained. Out of the number of questionnaires distributed, 161 responses were collected.

The research questionnaire was structured into two sections:

The first section contains questions to identify the respondents, so it was indicated that:

The majority of respondents were between 26 and 35 years of age, respectively $49 \%$ of them, $41 \%$ were in the range $26-35$ years, $7 \%$ were between 36 and 45 years and $3 \%$ were aged over 45 years.

Of the total number of respondents, the majority were female, $64 \%$, the male being $36 \%$.

With regard to the last level of graduate education, $63 \%$ of the graduates have graduated from the bachelor's degree program, $29 \%$ have completed the master's degree, $5 \%$ have just completed high school and 3\% had doctoral studies.

As regards the field of activity of the respondent company, the situation was as follows: 56 operated in retail, 52 in telecommunications and 53 in financial sector and banking.

Regarding the size of the company, 35\% of respondents worked in a company with over 8,000 employees, $33 \%$ fell in the range $5001-8000$ and $32 \%$ in 1000-5000.

The second section of the questionnaire was made up of questions to check the validity of the established hypotheses.

\subsection{Research Hypotheses}

The assumptions on which the study was based were as follows:

H1. If Bucharest improved its infrastructure, then the capital would be more attractive to the business environment, leading to increased urban competitiveness.

$364 \quad$ Review of International Comparative Management

Volume 19, Issue 4, October 2018 
H2. If local authorities were to provide tax incentives, then the number of foreign investors would increase, thus increasing the attractiveness and competitiveness of the city.

H3. If Bucharest would capitalize on its tourism potential, its attractiveness would increase, leading to increased competitiveness.

\section{Analysis and Results}

Question 6, 8 and 9 were used to test H1. Question 6 collected data on factors that influence urban competitiveness. Regarding the economic factors:

- The level of local salaries was appreciated by $74 \%$ of the respondents with "satisfactory", while the rest of respondents, $26 \%$, consider that this is "little satisfactory";

- The cost of living was appreciated by "not at all satisfactory" by the majority of respondents, i.e. 67\%. 30\% of the respondents noted "slightly satisfactory" and 3\% "satisfactory". Thus, it is noted that this factor is considered to be unsatisfactory and requires remedial action;

- $\quad 95 \%$ of respondents rated tourism as "satisfactory", 5\% believing it to be "less satisfactory".

On legislative factors (Figure 1):

- The local tax system was rated by 129 respondents as "less satisfactory" and 23 as "satisfactory". It can therefore be seen that it is perceived as being deficient in both application and value;

- Tax incentives are rated by 96 respondents as "satisfactory" and by 32 respondents as "little satisfactory";

- The development strategy of the city is judged to be "least satisfactory" by 145 respondents and by 7 as "not at all satisfactory".

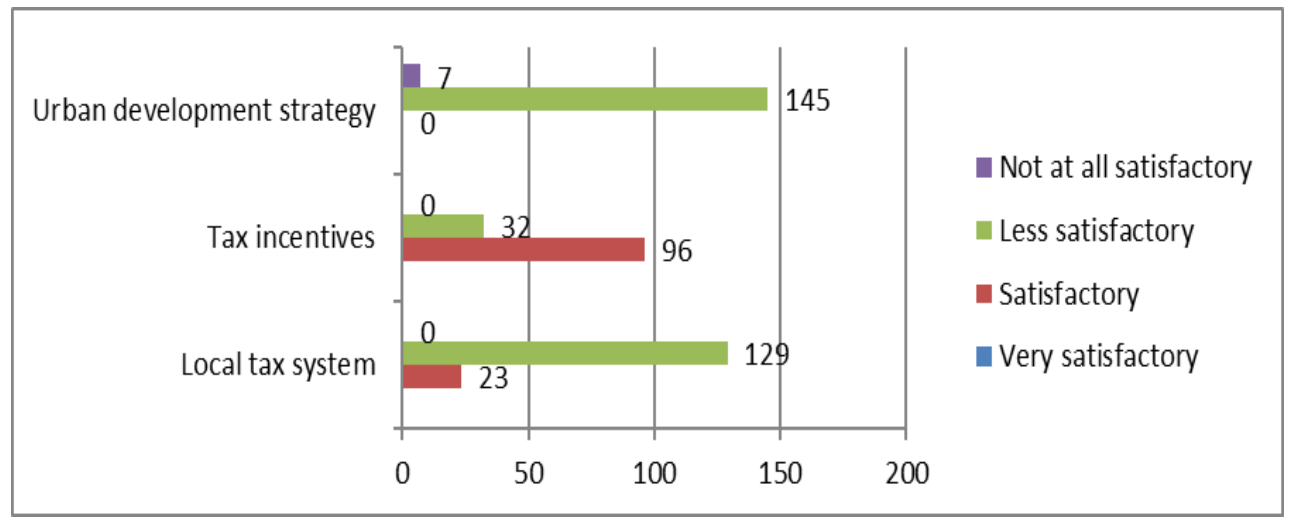

Figure 1. Satisfaction Level among Legislative Factors that Influence Urban Competitiveness by Company's Environment Needs

Source: Authors Based on Collected Data 
Physical Factors (Figure 2):

- The location of the city and the accessibility is appreciated by the majority of respondents, 144 as "satisfactory", only 8 respondents consider it "less satisfactory";

- Urban architecture is appreciated by 122 respondents as "satisfactory" and 11 are of the opinion that it is "not at all satisfactory";

- Infrastructure is perceived by all respondents as "not at all satisfactory".

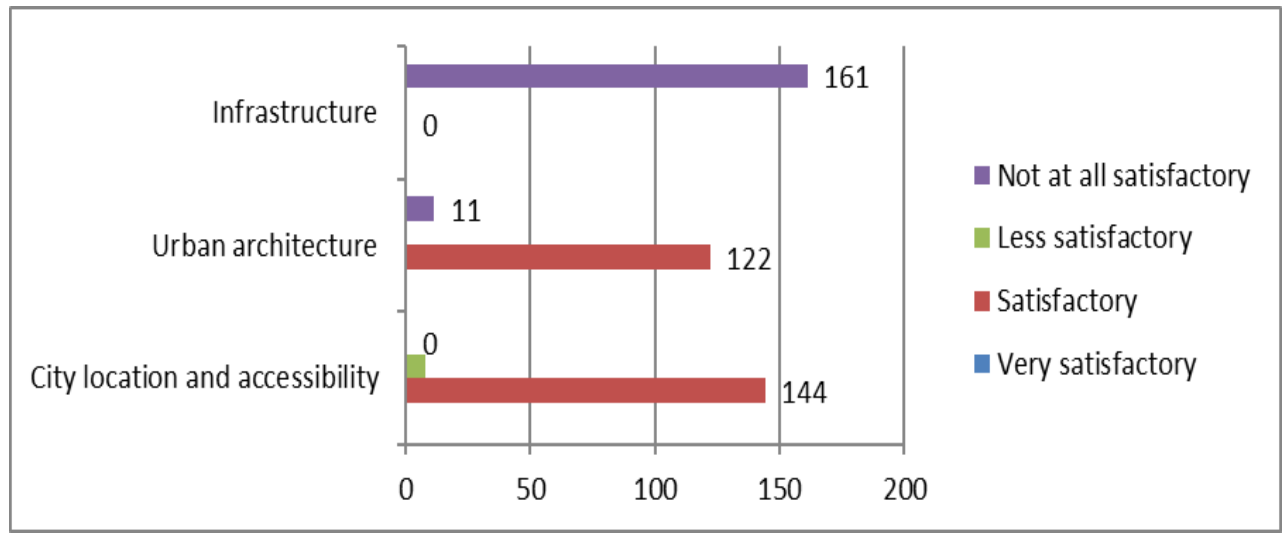

Figure 2. Satisfaction Level among Physical Factors that Influence Urban Competitiveness by Company's Environment Needs

Source: authors based on collected data

As for human factors (Figure 3):

- Local leaders are appreciated by the majority of respondents, 122 with "not at all satisfactory" 21 respondents with "less satisfactory" and 9 with "satisfactory";

- The innovation / creativity / talent of the locals is appreciated as "very satisfactory" by the majority, 98, and 54 as "satisfactory";

- The quality of the standard of living is appreciated by 78 respondents as "satisfactory", 59 respondents as "slightly satisfactory" and 15 respondents as "not at all satisfactory". 


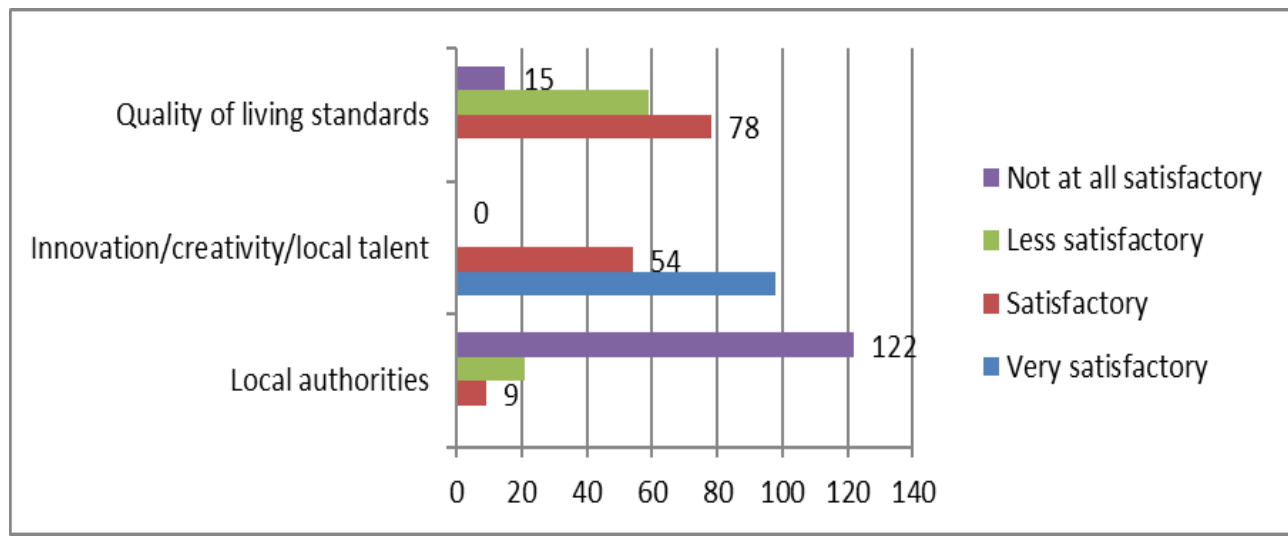

Figure 3. Satisfaction Level among Human Resource Factors that Influence Urban Competitiveness by Company's Environment Needs

Source: Authors Based on Collected Data

Question 8 was aimed at highlighting the main disadvantages of the company's location in Bucharest. Most of the respondents, i.e. $47 \%$, chose the poor infrastructure, $28 \%$ believe that congestion is a disadvantage, $23 \%$ the high level of taxes and taxes unlike other cities, and $8 \%$ considered as being a disadvantage, the inefficient cooperation between the public sector and the private one.

Question 9 aimed at identifying the degree of satisfaction with the state of Bucharest's infrastructure compared to other cities. The majority of the respondents, namely 101 of the total number of respondents, have chosen that the infrastructure is "not at all satisfactory", 45 that it is "little satisfactory", 15 considers it "satisfactory". It is noted that no respondent was of the opinion that the state of the capital's infrastructure is "very satisfactory", unlike other cities.

We can say that the first hypothesis is validated by the analysis of the results as a result of registering answers to questions $6,8,9$, the infrastructure proving to be the most important factor of attractiveness and urban competitiveness, the current state of which requires major improvements.

In order to test the $\mathrm{H} 2$ hypothesis, questions 7, 10, 11 and 12 were used.

Thus, question 7 sought to identify the reasons why the company also opened a head office in Bucharest. 140 respondents opted "to a large extent" on tourist attractions. Another reason, largely appreciated by 110 respondents, was the accessibility of the location. These are followed by access to prepared labour - 150 of our respondents believe that, to a certain extent, that was the reason that influenced the decision to open a headquarters in Bucharest. Access to transport lines is considered to be a minor influence.

Question 10 focused on identifying the most important factors underlying the decision to opt for opening a headquarters within a new city. The main factor considered is location accessibility, selected by $29 \%$ of respondents; it is followed by infrastructure - $26 \%$ of the respondents, $22 \%$ appreciate that facilities are important, and $4 \%$ that the local tax system is important. 
Regarding question 11 about whether the respondents would recommend to the partners of the company where they work to open headquarters in Bucharest, the majority, i.e. $75 \%$ would make this recommendation, while $25 \%$ of the respondents would not opt for this option.

Respondents answering question 11 were also asked to answer question 12 on why they would issue such a recommendation to the partners of the company they are working on in order to identify a possible measure to be taken by local authorities to increase the number of foreign investors.

Thus, $46 \%$ of the respondents believed that public-private partnerships would attract foreign investors, $30 \%$ that local taxes and exemptions are needed and $24 \%$ recommended a tax exemption on reinvested profits in Bucharest

As regards the validity of the second hypothesis, it was not confirmed because factors such as location accessibility or public-private partnerships are becoming more attractive and more important to foreign investors than tax incentives granted by the local authorities.

To test the third hypothesis, questions 13-18 were used.

The majority of respondents, 78, considered that Bucharest's priority urban development should be culture / tourism, followed by transport - 66 and trade - 11 . Of the respondents, 8 chose to complement the "other" option with education, health and industry (Figure 4). It is worth mentioning the importance of capitalizing on the tourist potential of the capital for its urban development.

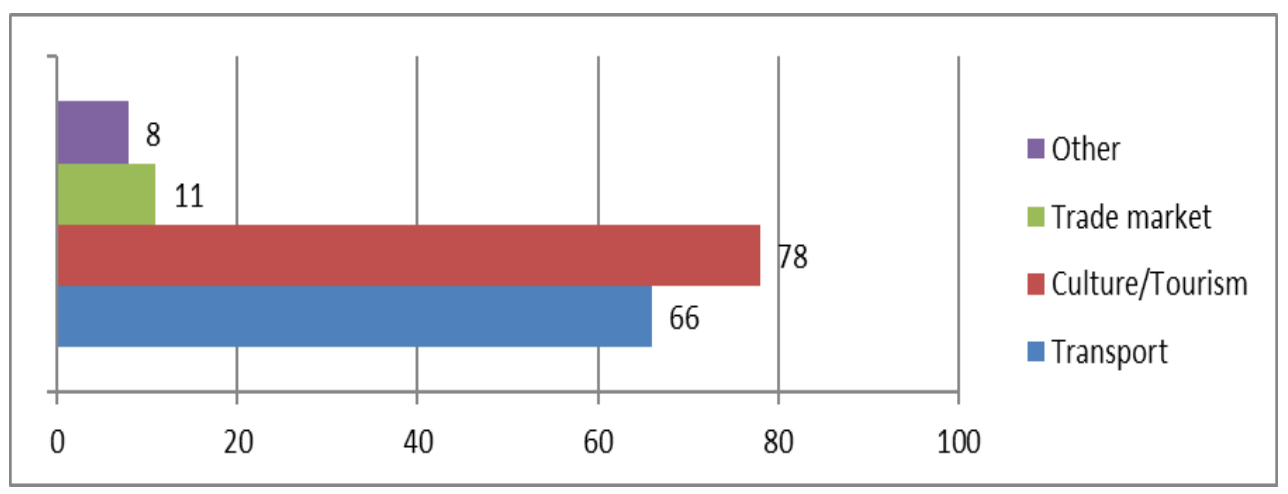

Figure 4. Main Directions in the Development of Bucharest Source: Authors Based on Collected Data

Question 14 sought to identify the main investments needed to be made by local authorities to increase the attractiveness of the city. It is noted that the most important investment is required to be in projects to improve services. The more aggressive promotion of the tourism of the capital city is in second place, followed by the elaboration and implementation of an urban strategy.

Question 15 aimed at identifying the reasons behind the decline in urban competitiveness of Bucharest in 2018 compared to 2017. The majority of respondents, 75 , consider that the poor promotion of tourism was the main reason 
for the reduction of competitiveness. 39 are of the opinion that changes in the political environment are the reason for the decline, 22 that the discontinuity of investment projects, and 16 that the stagnation of the implementation of an urban development strategy has led to a decrease in Bucharest's competitiveness (Figure $5)$.

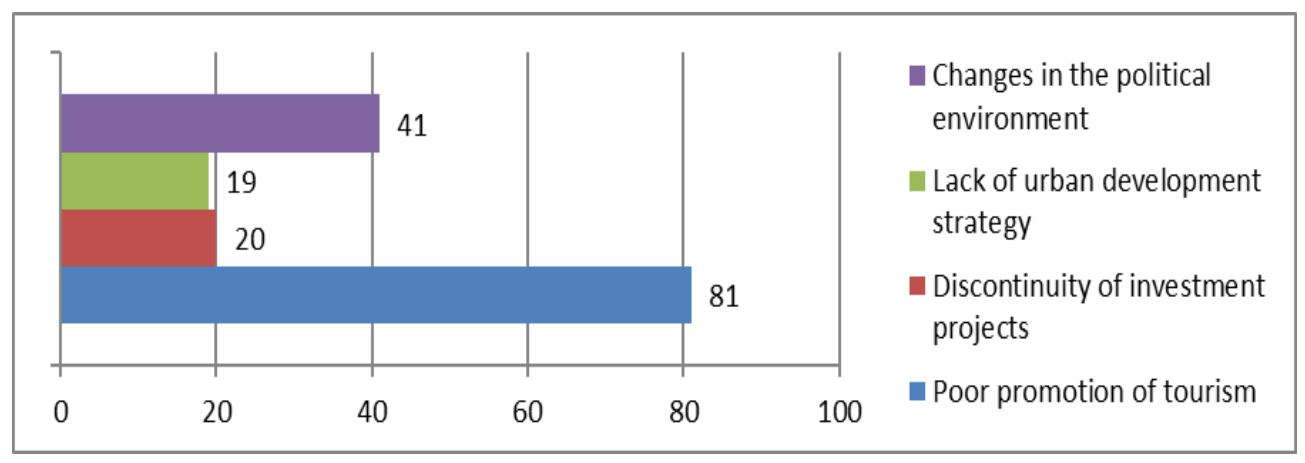

Figure 5. Main reasons for Bucharest's Decline in Urban Competitiveness from 2017 to 2018

Source: Authors Based on Collected Data

Through question 16 we wanted to learn about the degree of participation in the cultural events organized by the City Hall of Bucharest. Most respondents, $75 \%$, participated in such events, while $25 \%$ did not take part in them. There is an increased interest in such events, as $90 \%$ of respondents considered these events to be an attraction for Bucharest.

From the answers collected at question 18 it emerged that, in the opinion of the respondents, the capitalization of the tourist potential of Bucharest would increase the attractiveness that leads to the increase of the competitiveness, thus decreasing the decline registered in 2018 compared to the previous year.

The third hypothesis, by analysing the recorded results, was therefore verified as the importance of the tourist potential for increasing the attractiveness and implicitly of the urban competitiveness was noted.

\section{Conclusions}

Increasingly, cities are exposed to increased competition and need to improve their economic performance to keep up. There is greater pressure to increase factors that drive urban competitiveness, align economic infrastructure and facilitate increased trade and investment in cities and between cities in regional networks. Governments and stakeholders must ensure and manage the resources and investments needed to grow and develop urban economies.

Urban competitiveness is a combination of several factors that affect the performance of urban economies, including: quality of life, government response capacity, infrastructure, human resource development, local economy dynamics, 
and business costs. These key factors are used to assess the competitiveness of cities.

Strategies are needed to address the deficiencies and to leverage the forces of competition to ensure a fairer, more efficient and greener urban development. Competitiveness Enhancement Strategies attempt to create mechanisms by which cities: unlock their potential to attract investment and capital; develop their human capital base, infrastructure and knowledge; and develop their way out of poverty. Such a strategy would also mean for Bucharest an urban development step, increasing attractiveness and, implicitly, increasing urban competitiveness.

Effective urban planning and management are also required to manage population and economic growth, prevent environmental degradation and pollution, reduce congestion and address infrastructure and urban service issues. Central and local authorities need to work together to clarify administrative and financial responsibilities, improve enforcement of regulatory and enforcement laws, and maintain and optimize the use of public goods.

Integration and improvement of urban systems are needed to solve the increasingly crowded and expanded logistics and transport systems, which contribute significantly to the transaction costs and the costs of running and managing cities. Therefore, Bucharest's logistics and transport systems need to become more integrated, responsive and resilient to the changing needs of cities, businesses and governments; infrastructure needs to be adequately provided and improved to keep up with demand. Enhanced mobility networks improve connectivity and regional links.

Collaborative approaches to urban governance can be adopted as they help reduce the cost of business transactions, increase confidence and open opportunities for resource sharing, innovation and added value in city production and distribution systems. Streamlining and increasing tax efficiency, tax incentives, cutting red tape and partnerships for building research and innovation centres and industrial parks are important ways to promote collaboration. These approaches can be used to foster knowledge sharing and innovation, promote job creation, reduce business costs and enhance investor attractiveness and their confidence.

\section{References}

Beal, V., \& Pinson, G. (2014). When mayors go global: International strategies, urban governance and leadership. International Journal of Urban and Regional Research, 38(1), 302-317.

Begg, I. (Ed.). (2002). Urban competitiveness: policies for dynamic cities. Policy Press.

Buck, N. H., Gordon, I., Harding, A., \& Turok, I. (Eds.). (2005). Changing cities: Rethinking urban competitiveness, cohesion, and governance. Macmillan International Higher Education.

Carvalho, L., van den Berg, L., Galal, H., \& Teunisse, P. (Eds.). (2016). Delivering Sustainable Competitiveness: Revisiting the organising capacity of cities. Routledge.

$370 \quad$ Review of International Comparative Management

Volume 19, Issue 4, October 2018 
Corboș, R.A., Popescu, R.I. (2013). Competitivitatea organizațiilor culturale în contextul dezvoltării urbane. București: Editura ASE.

Esmaeilpoorarabi, N., Yigitcanlar, T., \& Guaralda, M. (2016). Place quality and urban competitiveness symbiosis? A position paper. International Journal of Knowledge-Based Development, 7(1), 4-21.

Jelier, R. W. (2017). European Cities and Global Competitiveness: Strategies for Improving Performance.

Kilroy, A. F., Mukim, M. and Negri, S. (2015). Documents \& Reports. [Online] Available at: http://documents.worldbank.org/curated/en/90241146799 0995484/pdf/101546-REVISED-Competitive-Cities-for-Jobs-andGrowth.pdf. [Accessed 6 August 2018].

Kornberger, M. (2012). Governing the city: From planning to urban strategy. Theory, Culture \& Society, 29(2), 84-106.

Kresl, P., Ietri, D. (2015). Urban Competitiveness: Theory and Practice. Routledge.

Martin, R., \& Simmie, J. (2008). The theoretical bases of urban competitiveness: does proximity matter? Revue d'Économie Régionale \& Urbaine, (3), 333-351.

Mukim, M. (2015, 10 22). Making cities competitive - What will it take? [Online] Available at: http://blogs.worldbank.org/psd/making-cities-competitivewhat-will-it-take. [Accessed 20 August 2018].

Ni, P., Kamiya, M., \& Ding, R. (2017). Cities Network Along the Silk Road: The Global Urban Competitiveness Report 2017. Springer.

Pengfei, N., \& Qinghu, H. (2006). Comparative research on the global urban competitiveness. Beijing, China: Chinese Academy for Social Sciences.

Sáez, L., \& Periáñez, I. (2015). Benchmarking urban competitiveness in Europe to attract investment. Cities, 48, 76-85.

Sinkiene, J. (2009). City Competitiveness: Concept, Factors, Model. In International conference current issues in management of business and society development.-Riga.-2009.-7-9 May.

Turok, I., Bailey, N., \& Docherty, I. (2004). Cities, Competitiveness and Cohesion: Evidence from Central Scotland.

Un-habitat. (2010). State of the world's cities 2010/2011: bridging the urban divide. Earthscan.

Wagner, J., Davies, S., Sorring, N., \& Vey, J. (2017). Advancing a New Wave of Urban Competitiveness: The Role of Mayors in the Rise of Innovation Districts.

Webster, D., \& Muller, L. (2000). Urban competitiveness assessment in developing country urban regions: The road forward. Washington DC: INFUD.

Zhang, M. (2014). What can cities do to enhance competitiveness? Local policies and actions for innovation. Urban Competitiveness and Innovation, 112.

Zhang, X., \& Corrie, B. P. (2018). Urban Competitive Analysis. In Investing in China and Chinese Investment Abroad (pp. 115-125). Springer, Singapore. 